Running Head: Dysphagia care in the community

\title{
Understanding dysphagia care in the community setting
}

\section{Acknowledgements}

The authors wish to acknowledge the speech language pathologists who participated in this study for sharing their practices and experiences, including those who took the time to pilot the survey and provide invaluable feedback. Thanks also go to research assistant, Georgina Klokman, who assisted with data analysis.

\begin{abstract}
Factors including health policy reform and the aging population are increasing demand for quality healthcare in the community. People with dysphagia are supported by speech-language pathologists (SLPs) in hospital and community settings, however little is known about the nature of dysphagia services offered by SLPs in the community. The aim of this study was to investigate SLP services and practices provided to community-based adults with dysphagia. A national cohort $(n=144)$ of SLPs working with community-based clients with dysphagia completed an online survey. Results revealed that clients with neurological conditions comprised the largest proportion of the caseload. Primary referral sources were family doctors (42.4\%) or other health professionals (37.5\%), with low rates of self-referral. Services were primarily delivered via individual sessions (84.1\%), usually within the client's home (80\% saw clients at home). While many clinicians were using both clinical and instrumental assessments, half had to refer clients to other services to access instrumental assessment. Most provided assessment and rehabilitation services, though few (28.5\%) reported using formal outcome or quality of life measures. Only 43.8\% referred or encouraged clients or caregivers to access support or social groups and few SLPs incorporated social participation or client well-being aspects in treatment. Speech-language pathology (SLP) practices in the community appear similar to what occurs in the acute setting, which are inherently biomedical. This may not be optimal care for clients with dysphagia who live at home and their caregivers. Further exploration about what clients and caregivers want from community-based SLP services is warranted.
\end{abstract}

Keywords: Dysphagia, clinician practices, community, deglutition, deglutition disorders

\section{Introduction}

Demands on healthcare services within the community context continue to grow globally, due to a shift towards providing care outside of the hospital setting. This change to the healthcare landscape has been driven by multiple factors. Health policy changes in many settings encourage early discharge from acute care services, with some facilities now offering 'hospital-at-home' care in lieu of an acute admission [1]. At the other end of the care continuum there is also increasing support for people to remain at home and out of nursing home/residential care for as long as possible [2,3]. Other influential factors include the aging population, people living with more chronic and complex conditions [4], and a shift to person-directed care and self-empowerment in healthcare [5-7]. This wave of service change is informed by consumer preference to remain at home where possible [8].

The increased demand for community-based services is putting healthcare systems under duress [4]. Management of complex and chronic conditions in the community requires input from a range of health care 
professionals and organisations, including speech-language pathologists (SLPs). Community healthcare professionals or services are often located in different settings, and work across sectors of the health system [9]. When such services are not executed in a strategic, aligned fashion, risks to the quality and safety of client care, as well as to client and caregiver satisfaction, arise. To meet the growing and diverse needs of the community, health professionals and services need to be accessible, coordinated, responsive and flexible.

Dysphagia is a sequela of many chronic and complex conditions such as stroke, Parkinson's disease (PD) and dementia, as well as the effects of advanced age. Multiple studies have examined the prevalence of dysphagia in the community, and report rates of between 11 and 37.6\% [10-13]. However, estimates dramatically increase for community-dwelling adults with health conditions known to be associated with dysphagia. For example, Bhattacharyya [14] conducted a national household survey in the United States, and found of those who reported swallowing difficulties, stroke was the most commonly reported aetiology. Similarly, in a cohort of 19 elderly participants with either stroke or PD living at home in The Netherlands, Bloem et al. [15] reported dysphagia presence in $47 \%$ of the cohort. For these individuals with dysphagia living in the community, dysphagia services are typically provided through designated SLP community-based roles.

There is a body of literature which has described SLP practice patterns for community management of other conditions such as aphasia [16-19]. However, little is documented about SLP practices to support people with dysphagia in the community. To date, studies about dysphagia management practices have primarily focused on the nature of SLP services in the acute or rehabilitation setting. While a small number of these studies have included some data from clinicians working in the community setting (e.g., [20,21]), the findings were described as a whole and differences between the acute and community service data could not be extrapolated. However, some information about SLP dysphagia practices in community-based settings can be drawn from two existing studies $[22,23]$, though it is important to note that the community setting was not the sole focus of the research. These studies by Rumbach et al. [22] and Steele et al. [23] used national surveys to explore dysphagia service delivery by SLPs across a range of settings (inpatient, outpatient, and community-based/in-home) in Australia and Canada respectively. The studies highlighted that variable practice patterns for dysphagia assessment and management exist, and setting variances were intermittently reported, meaning firm conclusions about community-based practices cannot be drawn $[22,23]$. Neither study explored concepts of holistic or psychosocial support for clients and caregivers. Other factors also limit the current relevance of the findings, including the fact that the Steele et al. [23] paper is now $>10$ years since publication and so may not reflect current practice, and the small numbers of community-based SLPs (24.68\%) in the total sample studied by Rumbach et al. [22] limits how representative the patterns may be of wider community practice.

Community-based services for dysphagia should differ from acute and center-based services for a number of reasons. Firstly, people with dysphagia have varying needs across the continuum of care and can be unique to the community setting. For example, it has been established that elderly adults with dysphagia in the community are likely to present with an increased risk of malnutrition and pneumonia [24,25]. Hence, this population may have different care needs. Indeed Rumbach et al. [22] noted differences in SLP dysphagia practice patterns across service settings, proposing that practice differences "may reflect the heterogeneous nature of dysphagia, and consequently the varying requirements for assessment and management of impaired swallowing in different settings" (p. 223).

Secondly, clinical practices may differ across settings due to policy drivers such as the rise of 'hospital-athome' care and person-directed care $[1,5-7]$. Such community practices require clinicians to be increasingly clientcentered and holistic in their approaches. At times this is in stark contrast to the acute setting where practices are 
often focussed on the immediate medical issues of the patient. Thirdly, there are key differences in the nature of community versus acute care management in other facets of speech pathology practice. For example, Verna et al. [19] found SLPs working with people with aphasia in the community used more treatments with a focus on life participation than the acute and rehabilitation setting, and intensive therapy in the community. This was reported to be far less common than in inpatient settings.

Finally, listening to the voices of clients themselves, individuals with dysphagia also differ in their concerns and support needs [26]. Responding to these needs requires different practices and even service models. In the Martino et al. [26] study, where qualitative methods were used to explore perceptions of patients with acute and chronic dysphagia, patients in the acute setting reported feeling fearful of choking to death and being overwhelmed by their new dysphagia. In contrast, people living with chronic dysphagia reported using a range of adaptive strategies to address dysphagic symptoms however, they expressed feeling depressed, anxious, frustrated and embarrassed as a result of their dysphagia [26]. Patients and SLPs were also found to differ in their views about the priorities of dysphagia management. Clinicians placed greatest significance on the biomedical aspects of dysphagia care (e.g., pulmonary or nutrition status) while patients across both acute and chronic stages felt the psychological aspects were of highest importance [26].

With more people with dysphagia likely being supported in the home and remaining at home for longer, it is imperative that practice patterns, and issues faced by SLPs managing the often complex needs of clients with dysphagia and their caregivers in the community, are better understood. Therefore, the aim of this study was to understand current community-based SLP services and practices provided to adults with dysphagia living at home. For the purposes of this paper, adults with dysphagia living at home as a population group will be referred to as community-based clients, and does not include people in acute or residential aged care settings.

\section{Method}

Participants

Participants were SLPs working in some capacity with community-based clients with dysphagia. Those working solely in inpatient hospital or residential aged care settings were excluded. Participants were recruited through an open invitation distributed to the membership of Speech Pathology Australia via a published notice in National e-news and the Speech Pathology Email Chats (SPECs) Google group. The invitation to participate was also emailed through the research team's professional networks. Within each of these dissemination groups, snowball sampling was encouraged, in which recipients were encouraged to pass on the invitation to other SLPs within their own networks to help maximize distribution and participation. For this reason a response rate cannot be determined, as the number of clinicians who received an invitation to participate in the survey is unknown. Ethical clearance to conduct the study was obtained through Griffith University human research ethics committee. All participants provided informed consent prior to completing the survey.

Survey Design

The survey design took place in three phases. First, the survey questions were designed by the research team, three of whom were experienced clinicians in dysphagia care and all had experience working in community services (SH, PC, EW). Two of the researchers also had considerable prior experience developing research questionnaires (PC, EW). Initial question development was informed by the team's personal experiences with community and dysphagia services and structured by the overarching research questions. Consideration was given to overall survey length to optimize clinician participation, and skip-logic were employed to reduce clinician exposure to questions which were not applicable to their practice context [27]. Questions were informed by the 
literature, with multiple simple question formats (yes/no responses, rankings, scales) employed to collect information easily and quickly. Short answer narrative response boxes were provided for questions where a closed response was not appropriate or where extra information could be provided [28].

The initial draft survey was then created using LimeSurvey (www.limesurvey.org), a secure, online survey design tool. Two phases of piloting were conducted prior to dissemination, to enhance reliability and content validity within the survey [29]. This piloting was conducted by a total of four SLPs working in community services, two in each phase. During the pilot, SLPs were asked to complete the survey as normal, and record time taken to complete survey. They were also asked to raise any issues they felt were not addressed by the draft questionnaire. Feedback from the SLPs in both rounds of pilot testing led to minor changes to the survey, predominantly related to wording and correction of technological issues. No additional questions were suggested for inclusion.

The final version of the full survey consisted of 47 questions covering a range of topics including demographics, clinical service management and SLP practices across assessment and intervention. Link to the full survey can be found in Appendix [for editor's decision if Appendix is provided within manuscript or as additional online material]. Participants required approximately 15 minutes to complete the survey. To address the current research aim, the following survey results are reported on: 1) Eligibility to participate, 2) Speech Language Pathologist Demographics, 3) Service Characteristics, 4) Caseload, 5) Service Policies and Governance, 6) Speech Language Pathology Management Practices, 7) Collaboration Practices, 8) Reporting and Outcome Measurement, 9) Speech Language Pathology Education Practices and 10) Service Strengths and Challenges. Results regarding sections 9) and 10) will be discussed in a subsequent manuscript.

\section{Procedure}

The online survey was made available to clinicians for an 8-week period, with a reminder notice disseminated after 4 weeks. Data from the survey were downloaded into Microsoft Excel and respondents who had indicated they did not meet the eligibility criteria or provided incomplete data sets (defined as surveys with $>60 \%$ of questions having 'no response') were removed. The data were then analysed using univariate descriptive statistics with IBM SPSS version 22.0. To ensure consistency in data reporting, for questions where a no-response was received from some participants, responses are reported as a percentage of the total number of respondents, including a percent non-response. For the two open ended questions, responses were categorized and tallied to reflect the different types of groups referred to (Q7bb) and the different outcome measures used (Q8aa and 8bb).

\section{Results}

A total of 182 clinicians accessed the survey. From this total, 38 data sets were subsequently removed, as respondents either indicated they were (a) ineligible to complete the survey and did not continue $(n=9)$, (b) were eligible but opted not to proceed beyond the eligibility questions $(n=6)$, or (c) did not respond to $>60 \%$ of the survey questions before exiting the survey $(n=23)$. Of the 23 respondents who did not complete the majority of the survey questions, all had exited the survey by the end of Question 4. The remaining 144 participant responses were included in the analysis.

\section{Speech-Language Pathologist Demographics}

Responses to the survey were obtained from SLPs in every Australian state and territory, with the highest proportion of respondents working in Queensland and New South Wales (see Table 1). The median number of years of experience was 9.04 (range $=6$ months to 44 years) with most indicating they were 'quite' or 'very' experienced at working with community-based clients with dysphagia. Just over half (51.4\%) of the participants reported 
working full time, and of those who reported working part time, the mean full time equivalent (FTE) was 0.47 (SD $=0.22$ ).

[Insert Table 1 about here]

\section{Clinical Services}

The location and type of dysphagia services are presented in Table 1. Just over half of services (56.9\%) were located in metropolitan areas and the vast majority were publicly funded (73.6\%) with only a small number of clinicians working in private practices and non-government organisations (NGOs). Participants indicated a median of 1.6 full-time equivalent staff (range $=.10$ to 30.00$)(n=140)$ per service were dedicated to providing dysphagia care to community-based clients.

Table 2 details the clinical populations who were seen by community-based SLP services for dysphagia. Results suggest that the large majority of services support a range of community-based populations with dysphagia, with very few services providing a single condition-specific service (e.g., solely for clients who have cancer). Dysphagia of neurological aetiology (stroke, traumatic brain injury [TBI], dementia, PD, Motor Neuron Disease [MND] and other progressive neurological conditions) accounted for the greatest overall population group being seen, and of these, stroke appeared to be the most common cohort, followed by PD.

[Insert Table 2 about here]

The majority ( $>90 \%)$ indicated that their services were able to accept referrals from family doctors or other health professionals $(93.1 \%)$ while three quarters $(73.6 \%)$ could also accept referrals directly from clients (i.e. selfreferral). In practice however, respondents noted that their current referrals predominantly came from family doctors (42.4\%) or other health professionals (37.5\%) while client-initiated referrals accounted for only $5.6 \%$.

SLPs were asked to indicate the clinical setting/s in which they saw community-based clients, and the proportion of their caseload they saw in each setting type (see Table 3). Results indicate services were provided across a range of settings however, a large proportion saw clients at the client's home ( $29 \%$ of respondents saw clients at home $90-100 \%$ of the time). A small proportion $9 \%(n=13)$ indicated that all $(100 \%)$ of their community clients were seen in a hospital setting, however half of these had indicated they saw clients post head and neck cancer management which is traditionally managed through hospital outpatient services.

[Insert Table 3 about here]

Most (75\%) clinicians worked in services that had no limit to the number of appointments they were able to provide for a community-based client with dysphagia. Of the $25 \%(\mathrm{n}=36)$ of clinicians who reported limitations to the number of sessions which could be provided, 22 respondents described policies regarding time-limited services; that is, services that could only see clients for a specified period of time (e.g., for a 6 week block of intervention). Those reporting policies about disease specific constraints (e.g., no limit for people with MND, but limits for those with other neurological conditions like PD and stroke), were few $(n=4)$. Restrictions were more common in public health services, and least likely in NGO and private services.

\section{Dysphagia Assessment Practices}

Assessment practices used with community-based clients with dysphagia are summarized in Table 4. All participants reported using clinical swallowing examinations and instrumental assessments in dysphagia diagnostics, however access to instrumental assessments was a noted issue. Only a small proportion had direct access to instrumental assessments within their workplace, though over half could gain indirect access to instrumental assessments through other local services. Use of fibre endoscopic evaluation of swallowing (FEES) was less common than videofluoroscopic swallowing study (VFSS); only eight participants reported frequent use with 
community-based clients. FEES was also available in fewer workplaces than VFSS, and all FEES occurred in public services and mostly (87.5\%) in metropolitan areas. Of those who reported having no access at all to any form of instrumental assessment $(n=7)$, five were working in regional or rural/remote settings. Variable use of adjunct tools such as cervical auscultation, pulse oximetry and cough reflex testing was noted.

[Insert Table 4 about here]

\section{Dysphagia Management Practices}

Over three quarters (77.1\%) of services reported providing ongoing monitoring and review of community-based clients with dysphagia. Nearly one third of SLPs reported seeing clients at least once weekly or more frequently (see Table 5). Intensive rehabilitation models were uncommon, with only 1 respondent reporting seeing clients daily (occurring in the private hospital/private outpatient setting). The majority of respondents (86.1\%) reported that an individual session model was the main mode in which they saw their clients (see Table 6). From the data, it was clear that group sessions were rarely used.

[Insert Tables $5 \& 6$ about here]

The majority (84.1\%) of SLPs reported using a combination of compensatory and rehabilitation techniques with only $15.9 \%(n=23)$ reporting only using compensatory techniques. Of those who reported using only compensatory strategies with their community-based clients, most were operating within a disability caseload. When asked to estimate the proportion of clients who required modification to food and fluid consistencies, almost three quarters of SLPs (73.5\%) indicated their clients required modification to food, compared with less than half (42.4\%) requiring modification to fluids. Respondents indicated that use of a free water protocol on a regular basis was limited, with only $13.2 \%$ responding they often recommend this and $16.7 \%$ never recommending this. The most common utilisation of a free water protocol was for 'select clients only' (70.1\%).

Multidisciplinary involvement in supporting people with dysphagia was also investigated (see Table 7). Collaboration with dietitians was reported as the most frequent in community-based dysphagia services, with $77.1 \%$ of SLPs indicating always or often working closely with that discipline. However for most of the professions listed in the survey, over $50 \%$ of the SLPs indicated they occasionally or never worked with these professions in their support of community-based dysphagia clients.

\section{[Insert Table 7 about here]}

Only $28.5 \%$ reported routine collection of functional impact or quality of life measures and only $25.7 \%$ reported routine collection of other types of outcome measures. Those who reported collecting outcome measures $(n=41)$, reported using a large range $(>20)$ of dysphagia-specific tools and more general tools. The most common dysphagia-specific tools were the Australian Therapy Outcome Measures [30] ( $n=23)$, and the SWAL-QOL [31] $(n=13)$. Of the general tools, the most common was the Canadian Occupational Performance Measure (COPM) [32] (14.6\%). Goal Attainment Scaling (GAS) [33] and establishing client-centered goals were also reported as a form of outcome measure by 19 SLPs.

\section{Carer and Related Psychosocial Supports}

Almost all participants (96.5\%) indicated they often or always involved caregivers in their dysphagia sessions. When asked whether they monitored for signs of anxiety and depression in their clients and caregivers, just under half reported doing this routinely for clients (47.9\%) and less for caregivers (38.2\%). Participants reported they monitored for anxiety and depression 'only if indicated' in $45.1 \%$ of clients and $47.2 \%$ of caregivers.

Only $43.8 \%$ of SLPs reported they referred or encouraged community-based clients with dysphagia and their caregivers to access support or social groups as part of their dysphagia care. NGO services were most likely to 
refer clients and caregivers to groups, and private hospital/private outpatient services were least likely. For those who did refer clients to support groups, these were primarily disease-specific support groups (e.g., a PD support group) and only four SLPs mentioned dysphagia-specific groups (all were cooking / modified diet education groups).

\section{Discussion}

The purpose of this study was to understand the current services and clinical practices of SLPs working with community-based clients with dysphagia. Results revealed that SLPs in the community context appear to be an experienced workforce, often seeing clients within the home or in community facilities and most services accepted client-initiated referrals. At one level these results would suggest that services are well placed operationally to provide client-directed care. However, although the majority of services could accept a client-initiated referral, only a very small number of services indicated that clients were a primary referral source. Rather the majority of referrals were received from medical and health professionals. A potential reason for this may relate to a lack of public awareness of the SLP role in dysphagia, resulting in individuals with a swallowing difficulty reporting to their family doctor or other health professional in the first instance. This potential lack of awareness of the SLP role is historical (e.g., [34]) and appears to be an ongoing issue [35,36]. Low self-referral rates may also be a direct consequence of dysphagia being a secondary outcome of another diagnosed condition (e.g., dysphagia post-stroke). As such, clients have most likely already been under the care of another health professional who facilitates the client's referral into a dysphagia service. Further examination of factors influencing client self-referral to community-based services is warranted.

Individuals with dysphagia due to acquired neurological aetiologies accounted for the largest population group being seen by SLPs in the community. This finding was expected given the well-established association between dysphagia and acquired and degenerative neurological conditions. The diagnostic populations constituting the majority of the caseloads were stroke and PD, however these data do not reflect the most prevalent neurological disease in the home environment, which is dementia [37]. The discrepancy may relate to onset patterns for dysphagia across these populations. Onset of dysphagia following stroke occurs in the acute stage and can persist following discharge home [38], while in PD, dysphagia can be one of the earliest symptoms and occurs in one third of individuals with PD living at home [39-41]. In contrast, dysphagia symptoms may not emerge in people with dementia until later in their disease progression, when changes to motor and sensory function become more pronounced, ultimately leading to dysphagia in up to $57 \%$ of individuals [42,43]. This may occur alongside a general increase in care requirements leading to residential care rather than management in the home.

While previous research suggests individuals with dysphagia differ in how they perceive and prioritize psychological issues in the acute stage compared with the chronic stage, [26], the current study found that SLP clinical practices in the community largely mirror what occurs in the acute setting (e.g., [44,45]). This raises the question then, about whether the needs of people with dysphagia and their caregivers in the community are being adequately assessed, understood and met. Indeed, parallels may be drawn from the head and neck cancer literature where research found patients desired ongoing access to dysphagia services and wanted support in the post-acute phase to make practical and emotional adjustments to living with dysphagia [46]. It is apparent that the psychosocial impacts of living with chronic dysphagia can be significant, and the voices of clients suggest that SLP practices may need to vary across contexts for client-centered care to occur $[26,46]$.

Assessment practices remained consistent with diagnostic principles (i.e. inclusive of a clinical swallowing examination and proceeding to instrumental measures as indicated) seen in acute services. Some service limitations 
were noted, with most community-based services gaining access to instrumental assessments through other services, and few having on-site instrumental assessment access. However, access to VFSS was problematic for only a small proportion (4.9\%). This finding contrasts with the only other study to investigate the availability of VFSS in the community [23] which found 35\% of SLPs working in the community did not have access to VFSS. The discrepancy may be a regional difference between Australia and Canada or it may be that in the 10 years since the Steele et al. [23] study was published, availability of instrumental assessment measures has increased. Access to FEES in the current study was significantly less than VFSS, with only $16.7 \%$ of respondents having access to FEES. This is likely because Australian SLPs must receive advanced training to conduct and interpret FEES, which can only occur in multidisciplinary healthcare setting [47]. While more SLPs are being trained in the use of FEES, the current lack of access to instrumental assessment for some community-based SLPs raises obvious challenges about assessment validity and treatment planning in the community setting.

This study found clinicians were undertaking active impairment-based interventions with their clients, primarily consisting of a combination of compensatory and rehabilitation approaches. The use of compensatory and rehabilitation techniques to address swallowing impairment is comparable to what occurs in the acute setting [48] and is suggestive of an ongoing active approach to rehabilitation for community-based clients. Few SLPs however provided dysphagia therapy services intensively. The most common model was 'other not specified' (29.2\%) which may suggest SLPs see community-based clients less frequently than once per month or 'as clinically indicated' rather than as a regular pattern of review. This result may also be indicative of client and service circumstances; Rumbach and colleagues [22] found SLPs conducted dysphagia sessions 'dependent upon patient ability to maintain therapy outside of sessions' (p. 7) or in line with current caseload constraints.

The current study also found that some multidisciplinary support for people with dysphagia continued within the community setting, though this was much less extensive than within acute services. Unlike acute or rehabilitation settings where multidisciplinary team access is facilitated by on-site staff, professional collaboration in the community requires active seeking out and coordination. The professionals most often involved in community-based dysphagia care in the current study were dietitians and medical doctors. This finding is similar to results in Rumbach et al.'s [22] study, where dietitians and general medical staff were reported in the top four professions involved in dysphagia care alongside nursing and ear, nose and throat (ENT) staff. These results were garnered across acute, rehabilitation and community contexts, however the majority of participants in the Rumbach et al. [22] study worked in the acute setting, suggesting that multidisciplinary dysphagia practices appear to be similar across both acute and community settings.

However, there were a few other professions that SLPs described having limited involvement with in the community setting, namely psychology and social work. Both the American Speech-Language Hearing Association and Speech Pathology Australia identify psychology and social work as key members of the dysphagia care team $[49,50]$. Both psychology and social work professionals can provide significant valued input to the lives of people with dysphagia and their caregivers in the community, recognising the long term psychosocial impacts of dysphagia [51] and the expressed wishes of clients [26]. While almost all SLPs reported involving caregivers in dysphagia sessions, few reported actively monitoring for signs of anxiety and depression in clients and caregivers and referring/encouraging clients and caregivers to access support or social groups as part of dysphagia care. This illustrates a discrepancy between the approach that SLPs take in dysphagia management and the approach that clients feel is needed. In a healthcare era where people are living longer with more chronic conditions and there is an increasing drive for healthcare to be client-centered and holistic, therefore it is important that community 
dysphagia services adopt a more interdisciplinary and multidisciplinary approach to supporting people with dysphagia.

Regarding the use of functional impact, quality of life and other outcome measures, the current study found these were not routinely collected in the majority of services. Rumbach et al. [22] explored the use of dysphagia outcome measures by SLPs working across acute, rehabilitation and community settings and likewise found SLP use of formal or published outcome measurement tools was minimal. SLPs reported the most common measure used was their informal judgement of clinical progress, followed by patient report of functional improvement and post-therapy re-assessment [22]. The current study confirms that the use of formal dysphagia outcome measures across clinical settings is limited. There are a number of issues with this observation. In the absence of formal routine dysphagia outcome measurement, it is impossible to validate that positive effects of treatment, and is difficult to justify to funding bodies and policy makers the effectiveness of SLP interventions. However, the reported limited use of formal measures may be due to reported lack of reliability and validity in dysphagia outcome measurement tools, or due to a lack of targeted-tools that transcend impairment-focused dysphagia management and consider psychosocial domains as suggested by Rosenbek and Donovan [52]. Rosenbek and Donovan [52] also suggest there may be too many outcome measurement tool options for clinicians in the impairment domain and a reduced number of these would be useful. Indeed in the current study, of the SLPs who reported using outcome measurement as part of their dysphagia management, over 20 different tools were mentioned.

\section{Limitations and Future Directions}

A limitation of this study is that the data were collected from one national context. Considering differences in health care services internationally, the extent to which current reported practice patterns can be assumed to be reflective of other contexts in difficult to determine. The inherent nature of survey data also presents some limitations; while this survey has provided an overview of current service characteristics and practices of SLPs working with dysphagia in the community, it provides limited insights into why certain patterns are evident in this service context. Further in-depth exploration is warranted before fully formed conclusions can be drawn. The current data also fail to provide any consumer perspective. It is essential that the perspectives of community-based adults with dysphagia and their caregivers regarding their experiences of SLP services, and what they both want and need from SLP services is explored. Without the voice of people with dysphagia and their significant others, it is difficult to plan strategies for enhanced service provision and innovation.

\section{Conclusion}

Within the community context, SLPs, health services and clients are not yet functioning in a way that transcends the biomedical model, or that engages with the broader biopsychosocial concerns of clients and families. While community-based services appear to be set up in a way that may enable principles of client-directed care, clinical practices appear to mirror the acute setting and may not be optimal care for clients with dysphagia who live at home. In light of government reforms, the rise of client-directed care and the ever-increasing demand for these services by an aging population, it is timely that dysphagia services for community-based adults receive attention. Until it can be fully understood what current practices are occurring, from the perspective of clinicians, clients and their families, SLP service provision for community-based clients with dysphagia risks being a duplication of an acute care model, without fully meeting the needs of the people who need support most; people with dysphagia and their family members. 


\section{Compliance with Ethical Standards}

Conflict of Interest: The authors report no conflicts of interest. The authors alone are responsible for the content and writing of the paper.

Ethical approval: All procedures performed in studies involving human participants were in accordance with the ethical standards of the institutional and/or national research committee and with the 1964 Helsinki declaration and its later amendments or comparable ethical standards.

\section{References}

1. Leff B. Hospital at Home: Feasibility and outcomes of a program to provide hospital-level care at home for acutely ill older patients. Ann Intern Med. 2005;143:798.

2. Bliss J, While AE. Meeting the needs of vulnerable patients: The need for team working across general practice and community nursing services. Lond J Prim Care. 2014;6:149-53.

3. Department of Health (2015). Help to Stay at Home. https://agedcare.health.gov.au/older-people-their-familiesand-carers/staying-at-home/help-to-stay-at-home Accessed 31 January 2018.

4. United Nations Department of Economic and Social Affairs Population Division (2015). World Population Ageing. Report No.: ST/ESA/SER.A/390.

http://www.un.org/en/development/desa/population/publications/pdf/ageing/WPA2015_Report.pdf Accessed 31 January 2018.

5. Lines LM, Lepore M, Wiener JM. Patient-centered, Person-centered, and Person-directed Care: They are not the same. Med Care. 2015;53:561-3.

6. Means R, Richards S, Smith R. Community care: policy and practice. 4th ed. Hampshire: Palgrave Macmillan; 2008 .

7. Australian Government. National Disability Insurance Scheme Act 2013. http://www.legislation.gov.au/Details/C2016C00894/Html/Text Accessed 1 August 2018.

8. Eckert JK, Morgan LA, Swamy N. Preferences for receipt of care among community-dwelling adults. J Aging Soc Policy. 2004;16:49-65.

9. Department of Health (2015). Better Outcomes for people with Chronic and Complex Health Conditions. https://www.health.gov.au/internet/main/publishing.nsf/Content/76B2BDC12AE54540CA257F72001102B9/\$File/ Primary-Health-Care-Advisory-Group Final-Report.pdf Accessed 31 January 2018.

10. Holland G, Jayasekeran V, Pendleton N, Horan M, Jones M, Hamdy S. Prevalence and symptom profiling of oropharyngeal dysphagia in a community dwelling of an elderly population: a self-reporting questionnaire survey. Dis Esophagus. 2011;24:476-80.

11. Kawashima K, Motohashi Y, Fujishima I. Prevalence of dysphagia among community-dwelling elderly individuals as estimated using a questionnaire for dysphagia screening. Dysphagia. 2004;19:266-71.

12. Lindgren S, Janzon L. Prevalence of swallowing complaints and clinical findings among 50-79-year-old men and women in an urban population. Dysphagia. 1991;6:187-92.

13. Roy N, Stemple J, Merrill RM, Thomas L. Dysphagia in the Elderly: Preliminary Evidence of Prevalence, Risk Factors, and Socioemotional Effects. Ann Otol Rhinol Laryngol. 2007;116:858-65.

14. Bhattacharyya N. The prevalence of dysphagia among adults in the United States. Otolaryngol-Head Neck Surg. 2014;151:765-9.

15. Bloem BR, Lagaay AM, Beek W van, Haan J, Roos RA, Wintzen AR. Prevalence of subjective dysphagia in community residents aged over 87. BMJ. 1990;300:721-2. 
16. Brown K, Worrall L, Davidson B, Howe T. Exploring speech-language pathologists' perspectives about living successfully with aphasia. Int J Lang Commun Disord. 2011;46:300-11.

17. Page C, Howell D. Current Clinical Practice of Speech-Language Pathologists who Treat Individuals with Aphasia: A Grounded Theory Study. J Interactional Res Commun Disord. 2014;6:1-23.

18. Rose M, Ferguson A, Power E, Togher L, Worrall L. Aphasia rehabilitation in Australia: Current practices, challenges and future directions. Int J Speech Lang Pathol. 2014;16:169-80.

19. Verna A, Davidson B, Rose T. Speech-language pathology services for people with aphasia: A survey of current practice in Australia. Int J Speech Lang Pathol. 2009;11:191-205.

20. Mathers-Schmidt BA, Kurlinski M. Dysphagia Evaluation Practices: Inconsistencies in clinical assessment and instrumental examination decision-making. Dysphagia. 2003;18:114-25.

21. Pettigrew CM, O’Toole C. Dysphagia evaluation practices of speech and language therapists in Ireland: Clinical assessment and instrumental examination decision-making. Dysphagia. 2007;22:235-44.

22. Rumbach A, Coombes C, Doeltgen S. A survey of Australian dysphagia practice patterns. Dysphagia. 2018;33:216-26.

23. Steele CM, Allen C, Barker J, Buen P, French R, Fedorak A, et al. Dysphagia service delivery by speechlanguage pathologists in Canada: Results of a national survey. 2007;31:12.

24. Loeb MB, Becker M, Eady A, Walker-Dilks C. Interventions to prevent aspiration pneumonia in older adults: a systematic review. J Am Geriatr Soc. 2003;51:1018-22.

25. Serra-Prat M, Palomera M, Gomez C, Sar-Shalom D, Saiz A, Montoya JG, et al. Oropharyngeal dysphagia as a risk factor for malnutrition and lower respiratory tract infection in independently living older persons: a populationbased prospective study. Age Ageing. 2012;41:376-81.

26. Martino R, Beaton D, Diamant NE. Perceptions of psychological issues related to dysphagia differ in acute and chronic patients. Dysphagia. 2010;25:26-34.

27. Couper MP. Designing Effective Web Surveys. Cambridge: Cambridge University Press; 2008.

28. Fowler F., Cosenza C. Writing effective questions. In: Leeuw ED de, Hox J, Dillman D, editors. International Handbook of Survey Methodology. New York ; London: Routledge; 2008. p. 136-60.

29. Rickards G, Magee C, Artino AR. You can't fix by analysis what you've spoiled by design: Developing survey instruments and collecting validity evidence. J Grad Med Educ. 2012;4:407-10.

30. Perry A, Skeat J. AusTOMS for Speech Pathology. Melbourne: La Trobe University; 2004.

31. McHorney CA, Bricker DE, Kramer AE, Rosenbek JC, Robbins J, Chignell KA, et al. The SWAL-QOL outcomes tool for oropharyngeal dysphagia in adults: I. Conceptual foundation and item development. Dysphagia. 2000;15:115-21.

32. Law M, Baptiste S, Carswell A, McColl M., Polatajko H., Pollock N. Canadian Occupational Performance Measure. 4th ed. Ottawa, ON: Canadian Association of Occupational Therapy Publications ACE; 2005.

33. Kiresuk TJ, Smith A, Cardillo JE, Library E ebook. Goal Attainment Scaling : Applications, Theory, and Measurement. New York; London : Psychology Press; 2014.

34. Breadner BW, Warr-Leeper GA, Husband SJ. A study of public awareness of speech-language pathology: Then and now. Hum Commun Can. 1987;18:10-3.

35. Byrne N. Why do students from related professions choose not to enter speech-language pathology? Int J Speech Lang Pathol. 2010;12:344-51. 
36. Greenwood N, Wright JA, Bithell C. Perceptions of speech and language therapy amongst UK school and college students: implications for recruitment. Int J Lang Commun Disord. 2006;41:83-94.

37. Danila O, Hirdes JP, Maxwell CJ, Marrie RA, Patten S, Pringsheim T, et al. Prevalence of neurological conditions across the continuum of care based on interRAI assessments. BMC Health Serv Res. 2014;14:1-14.

38. Mann G, Hankey GJ, Cameron D. Swallowing function after stroke: prognosis and prognostic factors at 6 months. Stroke. 1999;30:744-8.

39. Kalf JG, Swart BJM de, Bloem BR, Munneke M. Prevalence of oropharyngeal dysphagia in Parkinson's disease: A meta-analysis. Parkinsonism Relat Disord. 2012;18:311-5.

40. Miller N, Noble E, Jones D, Burn D. Hard to swallow: dysphagia in Parkinson's disease. Age Ageing. 2006;35:614-8.

41. Walker RW, Dunn JR, Gray WK. Self-reported dysphagia and its correlates within a prevalent population of people with Parkinson's disease. Dysphagia. 2011;26:92-6.

42. Alagiakrishnan K, Bhanji RA, Kurian M. Evaluation and management of oropharyngeal dysphagia in different types of dementia: A systematic review. Arch Gerontol Geriatr. 2013;56:1-9.

43. Langmore SE, Olney RK, Lomen-Hoerth C, Miller BL. Dysphagia in patients with frontotemporal lobar dementia. Arch Neurol. 2007;64:58.

44. Geeganage C, Beavan J, Ellender S, Bath PMW. Interventions for dysphagia and nutritional support in acute and subacute stroke. Cochrane Database Syst Rev. 2012;10:CD000323.

45. Kertscher B, Speyer R, Palmieri M, Plant C. Bedside screening to detect oropharyngeal dysphagia in patients with neurological disorders: An updated systematic review. Dysphagia. 2014;29:204-12.

46, Nund RL, Ward EC, Scarinci NA, Cartmill B, Kuipers P, Porceddu SV. Survivors' experiences of dysphagiarelated services following head and neck cancer: Implications for clinical practice. Int J Lang Commun Disord. 2014;49:354-63.

47. Speech Pathology Australia. Position Paper: Fibreoptic Endoscopic Evaluation of Swallowing (FEES). Speech Pathology Australia: Melbourne; 2007.

48. Schindler A, Vincon E, Grosso E, Miletto AM, Rosa RD, Schindler O. Rehabilitative management of oropharyngeal dysphagia in acute care settings: Data from a large Italian teaching hospital. Dysphagia. 2008;23:230-6.

49. American Speech-Language-Hearing Association. Adult Dysphagia: Overview (n.d.). https://www.asha.org/Practice-Portal/Clinical-Topics/Adult-Dysphagia/ Accessed 31 January 2018.

50. Speech Pathology Australia. Clinical Guideline: Dysphagia. Speech Pathology Australia: Melbourne; 2012.

51. Nund RL, Ward EC, Scarinci NA, Cartmill B, Kuipers P, Porceddu SV. The lived experience of dysphagia following non-surgical treatment for head and neck cancer. Int J Speech Lang Pathol. 2014;16:282-9.

52. Rosenbek J, Donovan N. Oropharyngeal dysphagia outcome measurement. In: Cichero JA., Murdoch B., editors. Dysphagia Found Theory Pract. Chichester, England: John Wiley \& Sons; 2006. p. 543-66. 
Table 1: Demographic information of participants $(n=144)$.

\begin{tabular}{|c|c|c|}
\hline & $n=144$ & Percentage (\%) \\
\hline \multicolumn{3}{|l|}{ Place of employment } \\
\hline Australian Capital Territory & 2 & 1.4 \\
\hline New South Wales & 47 & 32.6 \\
\hline Northern Territory & 2 & 1.4 \\
\hline Queensland & 50 & 34.7 \\
\hline South Australia & 9 & 6.3 \\
\hline Tasmania & 3 & 2.1 \\
\hline Victoria & 24 & 16.7 \\
\hline Western Australia & 7 & 4.9 \\
\hline \multicolumn{3}{|l|}{ Location } \\
\hline Metropolitan & 82 & 56.9 \\
\hline Regional & 42 & 29.2 \\
\hline Rural and/or Remote & 20 & 13.9 \\
\hline \multicolumn{3}{|l|}{ Workplace Type } \\
\hline Public/Government health service & 106 & 73.6 \\
\hline Private Practice & 16 & 11.1 \\
\hline $\begin{array}{l}\text { Non-government organisation } \\
(\mathrm{NGO})\end{array}$ & 15 & 10.4 \\
\hline $\begin{array}{l}\text { Private sector (e.g., private } \\
\text { hospital) }\end{array}$ & 5 & 3.5 \\
\hline Other & 2 & 1.4 \\
\hline \multicolumn{3}{|c|}{ Experience working with community-based dysphagia } \\
\hline No experience & 1 & .7 \\
\hline Limited experience & 9 & 6.3 \\
\hline Some experience & 25 & 17.4 \\
\hline Quite experienced & 58 & 40.3 \\
\hline Very experienced & 51 & 35.4 \\
\hline \multicolumn{3}{|c|}{ Nature of community-based dysphagia work } \\
\hline Full time & 74 & 51.4 \\
\hline Part time & 70 & 48.6 \\
\hline
\end{tabular}


Table 2: Population groups seen by community-based dysphagia services.

Number of respondents indicating the proportion of conditions associated with dysphagia on their caseload.

\begin{tabular}{|c|c|c|c|c|c|c|}
\hline \multirow[b]{2}{*}{ Condition } & \multicolumn{6}{|c|}{ Proportion of Caseload } \\
\hline & $0 \%$ & $1-24 \%$ & $25-49 \%$ & $50-74 \%$ & $75-99 \%$ & $100 \%$ \\
\hline Stroke & 39 & 53 & 24 & 27 & 0 & 1 \\
\hline TBI & 82 & 57 & 4 & 1 & 0 & 0 \\
\hline Dementia & 58 & 77 & 8 & 1 & 0 & 0 \\
\hline Parkinson's disease & 44 & 72 & 22 & 6 & 0 & 0 \\
\hline Motor Neuron Disease & 68 & 70 & 6 & 0 & 0 & 0 \\
\hline Other progressive neurological condition & 53 & 87 & 3 & 0 & 1 & 0 \\
\hline Cancer & 70 & 59 & 4 & 2 & 1 & 8 \\
\hline Psychogenic/Anxiety & 118 & 25 & 1 & 0 & 0 & 0 \\
\hline Disability & 88 & 30 & 5 & 4 & 3 & 14 \\
\hline General aging & 62 & 72 & 8 & 1 & 1 & 0 \\
\hline Unknown & 111 & 30 & 3 & 0 & 0 & 0 \\
\hline Other not specified & 129 & 12 & 2 & 1 & 0 & 0 \\
\hline
\end{tabular}


Table 3: Clinical settings where adults with dysphagia who live at home are seen.

Number of respondents who indicated seeing clients with dysphagia across various clinical settings.

\begin{tabular}{|c|c|c|c|c|c|c|}
\hline \multirow[b]{2}{*}{ Setting Type } & \multicolumn{6}{|c|}{ Proportion of Caseload } \\
\hline & $0 \%$ & $1-24 \%$ & $25-49 \%$ & $50-74 \%$ & $75-99 \%$ & $100 \%$ \\
\hline Client's home & 28 & 22 & 16 & 28 & 21 & 29 \\
\hline Community Health Center & 101 & 18 & 13 & 5 & 4 & 3 \\
\hline Outpatient Rehabilitation Unit & 119 & 4 & 8 & 6 & 6 & 1 \\
\hline Inpatient Rehabilitation Unit & 129 & 3 & 6 & 5 & 1 & 0 \\
\hline Acute Hospital & 106 & 7 & 6 & 10 & 2 & 13 \\
\hline Private Practice Clinic & 137 & 2 & 1 & 2 & 1 & 1 \\
\hline Other & 115 & 10 & 4 & 10 & 3 & 2 \\
\hline
\end{tabular}

$n=144$ 
Table 4: Assessment practices of SLPs seeing adults with dysphagia who live at home.

\begin{tabular}{|c|c|c|c|c|c|c|}
\hline & \multirow{2}{*}{$\begin{array}{c}\text { Clinical } \\
\text { Clinical Swallow } \\
\text { Examination } \\
(n=143)\end{array}$} & \multicolumn{2}{|c|}{ Instrumental } & \multicolumn{3}{|c|}{ Adjunct Tools } \\
\hline & & $\begin{array}{c}\text { VFSS / MBS } \\
\quad(n=143)\end{array}$ & $\begin{array}{c}\text { FEES } \\
(n=142)\end{array}$ & $\begin{array}{c}\text { Cervical } \\
\text { Auscultation } \\
(n=141)\end{array}$ & $\begin{array}{l}\text { Pulse Oximetry } \\
\qquad(n=141)\end{array}$ & $\begin{array}{l}\text { Cough Reflex } \\
\text { Testing } \\
(n=141)\end{array}$ \\
\hline $\begin{array}{l}\text { Not available at my workplace and I } \\
\text { have no access to this service. }\end{array}$ & $0(0 \%)$ & $7(4.9 \%)$ & $41(28.5 \%)$ & $25(17.4 \%)$ & $45(31.3 \%)$ & $85(59 \%)$ \\
\hline $\begin{array}{l}\text { Not available at my workplace } \\
\text { however we have services we can refer } \\
\text { client to for this assessment. }\end{array}$ & $1(0.7 \%)$ & $77(53.5 \%)$ & $77(53.5 \%)$ & $7(4.9 \%)$ & $16(11.1 \%)$ & $18(12.5 \%)$ \\
\hline $\begin{array}{l}\text { Available at my workplace but I never } \\
\text { use. }\end{array}$ & $0(0 \%)$ & $0(0 \%)$ & $4(2.8 \%)$ & $32(22.2 \%)$ & $27(18.8 \%)$ & $20(13.9 \%)$ \\
\hline $\begin{array}{l}\text { Available at my workplace but I only } \\
\text { use occasionally. }\end{array}$ & $5(3.5 \%)$ & $24(16.7 \%)$ & $12(8.3 \%)$ & $26(18.1 \%)$ & $39(27.1 \%)$ & $11(7.6 \%)$ \\
\hline $\begin{array}{l}\text { Available at my workplace and I use } \\
\text { frequently in my practice. }\end{array}$ & $137(95.1 \%)$ & $35(24.3 \%)$ & $8(5.6 \%)$ & $51(36.2 \%$ & $14(9.7 \%)$ & $7(4.9 \%)$ \\
\hline
\end{tabular}


Table 5: Frequency of service provision to adults with dysphagia who live at home.

\begin{tabular}{lcc}
\hline Time & $\boldsymbol{n}$ & Percentage (\%) \\
\hline Daily & 1 & 0.7 \\
$1-2$ times per week & 20 & 13.9 \\
Once per week & 26 & 18.1 \\
Fortnightly & 28 & 19.4 \\
Monthly & 27 & 18.8 \\
Other & 42 & 29.2 \\
\hline Total & 144 & 100 \\
\hline
\end{tabular}


Table 6: Service delivery models utilized for adults with dysphagia who live at home.

\begin{tabular}{|c|c|c|c|c|}
\hline & Always & Often & Occasionally & Never \\
\hline $\begin{array}{l}\text { Individual treatment } \\
\text { sessions only } \\
(\mathrm{n}=144)\end{array}$ & $124(86.1 \%)$ & $18(12.5 \%)$ & $2(1.4 \%)$ & $0(0 \%)$ \\
\hline $\begin{array}{l}\text { Group and Individual } \\
\text { treatment sessions only } \\
(\mathrm{n}=118)\end{array}$ & $1(0.7 \%)$ & $3(2.1 \%)$ & $22(15.3 \%)$ & $92(63.9 \%)$ \\
\hline $\begin{array}{l}\text { Group treatment sessions } \\
\text { only } \\
(\mathrm{n}=114)\end{array}$ & $1(0.7 \%)$ & $0(0 \%)$ & $6(4.2 \%)$ & $107(74.3 \%)$ \\
\hline
\end{tabular}


Table 7: Members of the multidisciplinary team SLPs indicated working with in the management of adults with dysphagia living at home.

\begin{tabular}{|c|c|c|c|c|}
\hline & Always & Often & Occasionally & Never \\
\hline $\begin{array}{l}\text { Family doctor } \\
(\mathrm{n}=141)\end{array}$ & $25(17.4 \%)$ & $51(35.4 \%)$ & $62(43.1 \%)$ & $3(2.1 \%)$ \\
\hline $\begin{array}{l}\text { Medical Specialist } \\
(\mathrm{n}=138)\end{array}$ & $9(6.3 \%)$ & $46(31.9 \%)$ & $68(47.2 \%)$ & $15(10.4 \%)$ \\
\hline $\begin{array}{l}\text { Nursing staff } \\
(\mathrm{n}=140)\end{array}$ & $8(5.6 \%)$ & $43(29.9 \%)$ & $66(45.8 \%)$ & $23(16 \%)$ \\
\hline $\begin{array}{l}\text { Dietitian } \\
(\mathrm{n}=143)\end{array}$ & $34(23.6 \%)$ & $77(53.5 \%)$ & $28(19.4 \%)$ & $4(2.8 \%)$ \\
\hline $\begin{array}{l}\text { Occupational Therapist } \\
(\mathrm{n}=141)\end{array}$ & $6(4.2 \%)$ & $51(35.4 \%)$ & $70(48.6 \%)$ & $14(9.7 \%)$ \\
\hline $\begin{array}{l}\text { Pharmacist } \\
(\mathrm{n}=142)\end{array}$ & $0(0 \%)$ & $21(14.6 \%)$ & $84(58.3 \%)$ & $37(25.7 \%)$ \\
\hline $\begin{array}{l}\text { Physiotherapist } \\
(\mathrm{n}=143)\end{array}$ & $3(2.1 \%)$ & $43(29.9 \%)$ & $76(52.8 \%)$ & $21(14.6 \%)$ \\
\hline $\begin{array}{l}\text { Psychologist } \\
(\mathrm{n}=142)\end{array}$ & $1(0.7 \%)$ & $9(6.3 \%)$ & $78(54.2 \%)$ & $54(37.5 \%)$ \\
\hline $\begin{array}{l}\text { Social Worker } \\
(n=139)\end{array}$ & $0(0 \%)$ & $29(20.1 \%)$ & $70(48.6 \%)$ & $40(27.8 \%)$ \\
\hline
\end{tabular}

